\title{
Response to: Comment on "48-Week Outcome after Cessation of Nucleos(t)ide Analogue Treatment in Chronic Hepatitis B Patient and the Associated Factors with Relapse"
}

\author{
Wen-xiong $X u \mathbb{D}^{1,2}$ and Liang Peng $\mathbb{D i D}^{1,2}$ \\ ${ }^{1}$ Department of Infectious Diseases, Third Affiliated Hospital of Sun Yat-sen University, Guangzhou 510630, Guangdong, China \\ ${ }^{2}$ Guangdong Key Laboratory of Liver Disease Research, Third Affiliated Hospital of Sun Yat-sen University, \\ Guangzhou 510630, Guangdong, China
}

Correspondence should be addressed to Liang Peng; pzp33@hotmail.com

Received 3 April 2019; Accepted 9 April 2019; Published 2 May 2019

Academic Editor: Kevork M. Peltekian

Copyright (c) 2019 Wen-xiong Xu and Liang Peng. This is an open access article distributed under the Creative Commons Attribution License, which permits unrestricted use, distribution, and reproduction in any medium, provided the original work is properly cited.

We appreciate the interest of Yafei Guo and colleagues [1] in our publication [2]. We agree with Guo et al. that nucleos(t)ide analogues (NAs) cessation can be recommended in chronic hepatitis $\mathrm{B}(\mathrm{CHB})$ patients who are relatively younger and have relatively low serum hepatitis B surface antigen (HBsAg) levels and that it may be more effective to add on interferon treatment as an immune modulation rather than NAs cessation for $\mathrm{CHB}$ patients with low-level HBsAg.

In our study, we recruited patients with undetected HBV DNA for a period of time before NAs cessation, which is described in the inclusion criteria, according to the guidelines of prevention and treatment of $\mathrm{CHB}$ from the Asian Pacific Association for the Study of the Liver (APASL) [3]. Although 39 of 62 patients experienced virologic relapse in our study, 14 patients changed to the nonrelapse group, with a relatively low level of HBV DNA. This may be a balance between the virus and host immunity, which results from immune recovery and self-control by the patients themselves [4]. Although the number of these patients is small, we think NAs cessation can be achieved in case of long-term follow-up.

In 10 patients with HBsAg clearance before NAs cessation, HBsAg clearance and undetectable HBV DNA are maintained throughout follow-up. These patients are "functionally cured". So NAs cessation in patients with HBsAg clearance is achievable. For CHB patients with low-level HBsAg, NAs cessation can be recommend by a systematic review [5]. Switching to or adding on interferon alpha treatment can be another choice for those who have not contraindications and who can afford the treatment, as interferon alpha is an immune modulator. A study of NAs cessation and switching to interferon alpha treatment in $\mathrm{CHB}$ patients with low-level $\mathrm{HBs} \mathrm{Ag}$ is proceeding to achieve HBsAg seroconversion right now in our team. The results were presented at the 2018 AASLD Liver Meeting [6].

There are few parameters, such as HBsAg or pgRNA, for predicting relapse and NAs retreatment in $\mathrm{CHB}$ patients. Further study is needed.

\section{Conflicts of Interest}

The authors declare that they have no conflicts of interest.

\section{References}

[1] Y. Guo and L. Wang, "Comment on "48-week outcome after cessation of nucleos(t)ide analogue treatment in chronic hepatitis B patient and the associated factors with relapse"," Canadian Journal of Gastroenterology and Hepatology, vol. 2019, Article ID 4927083, 2 pages, 2019. 
[2] Wen-xiong Xu, Qian Zhang, Xiang Zhu et al., “48-week outcome after cessation of nucleos(t)ide analogue treatment in chronic hepatitis B patient and the associated factors with relapse," Canadian Journal of Gastroenterology and Hepatology, vol. 2018, Article ID 1817680, 11 pages, 2018.

[3] Y. F. Liaw, J. H. Kao, T. Piratvisuth, H. L. Chan, R. N. Chien, C. J. Liu et al., "Asian pacific association for the study of the liver. Asian-pacific consensus statement on the management of chronic hepatitis B: a 2012 update," Journal of Gastroenterology and Hepatology, vol. 6, pp. 531-561, 2012.

[4] E. Zhang, A. Kosinska, M. Lu, H. Yan, and M. Roggendorf, "Current status of immunomodulatory therapy in chronic hepatitis B, fifty years after discovery of the virus: Search for the "magic bullet" to kill cccDNA," Antiviral Research, vol. 123, pp. 193-203, 2015.

[5] J. Liu, T. Li, L. Zhang et al., "The role of hepatitis B surface antigen in nucleos $(\mathrm{t})$ ide analogues cessation among asian chronic hepatitis B patients: a systematic review," Hepatology, 2018.

[6] Z. Gao, X. Zhu, B. Lin et al., "The optimizing treatment of peg interferon alfa in hbeag negative chronic hepatitis b patients with low level HBsAg: a multicenter real world study (interferon cure study, i cure study)," Hepatology, no. 246A, Poster no. 413, 2018. 


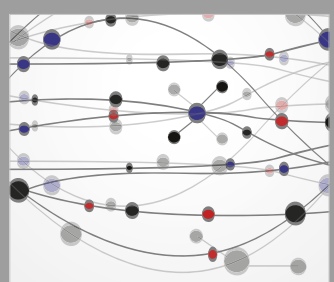

The Scientific World Journal
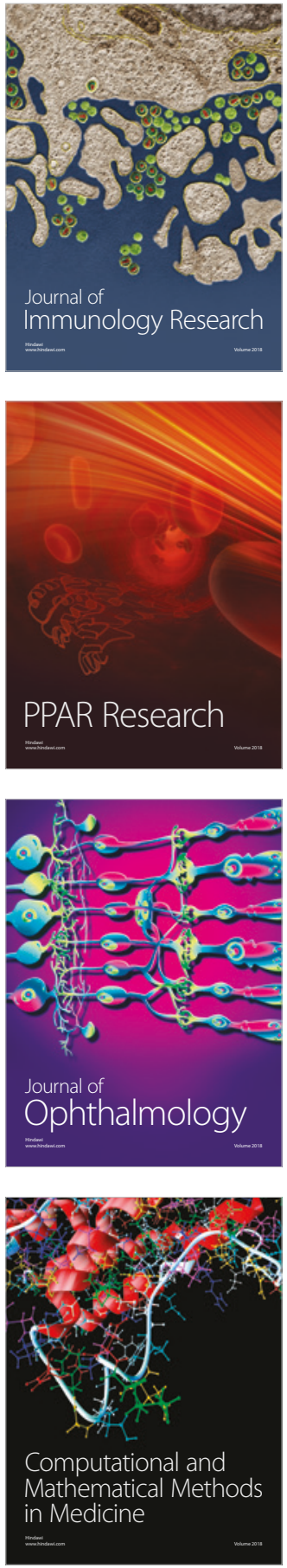

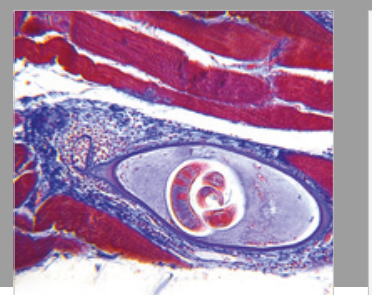

Gastroenterology Research and Practice

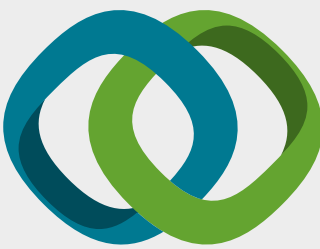

\section{Hindawi}

Submit your manuscripts at

www.hindawi.com
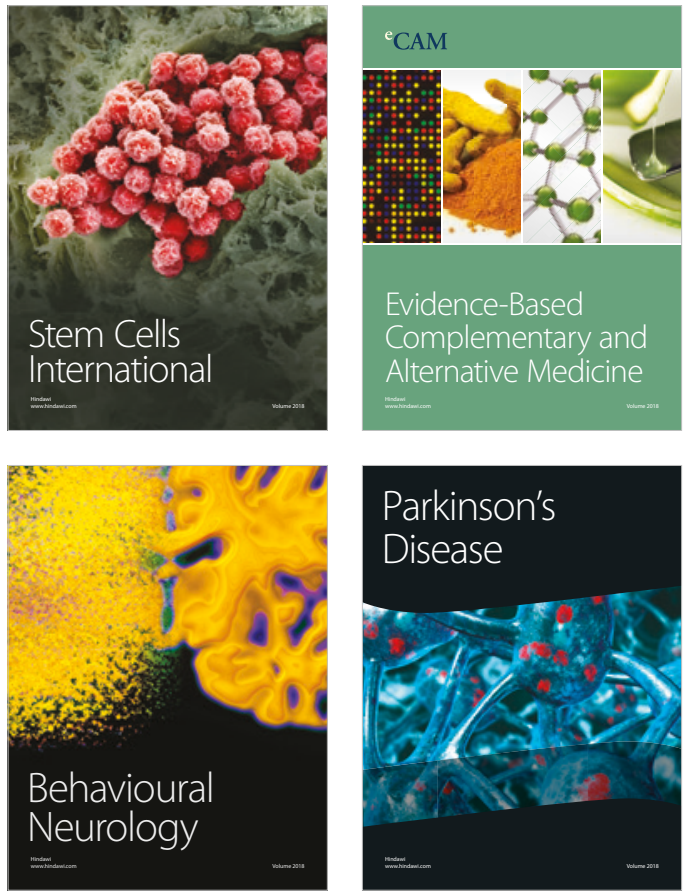

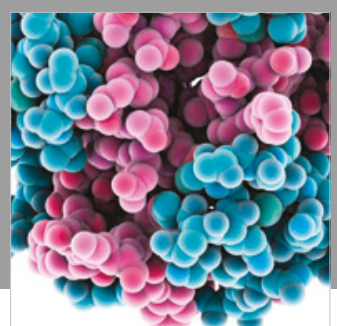

ournal of

Diabetes Research

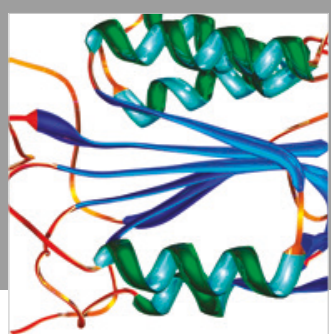

Disease Markers
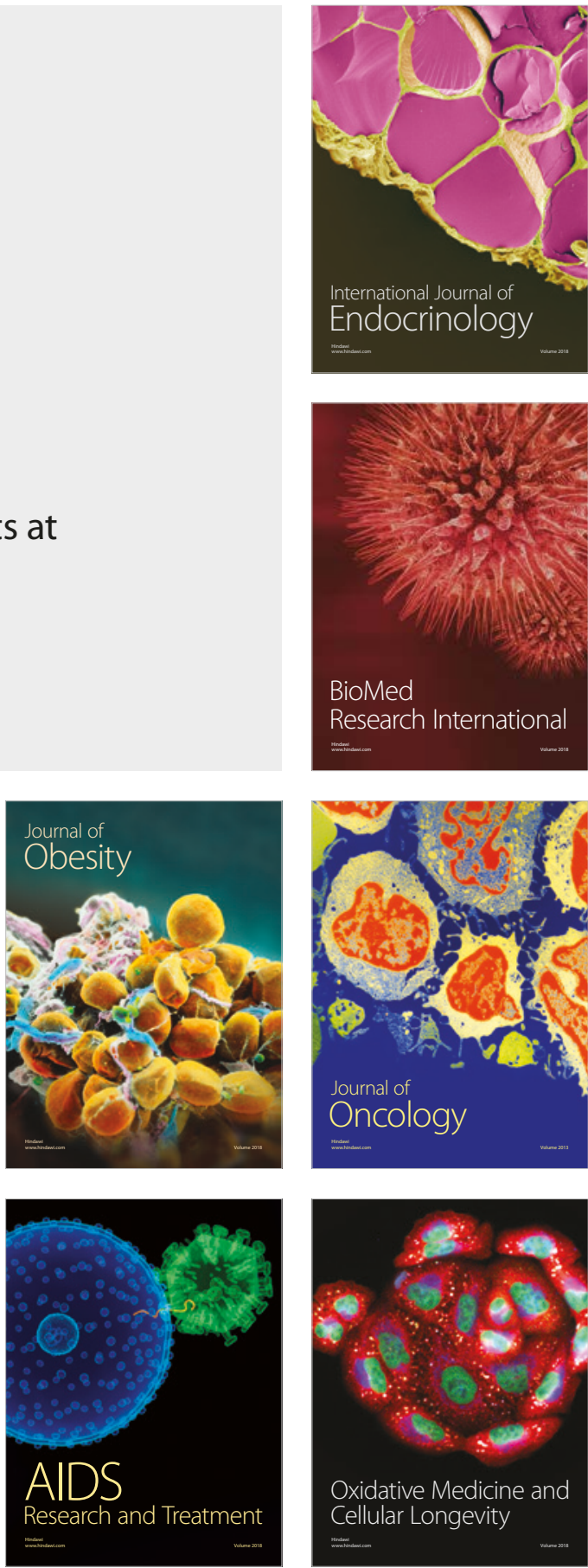